- hanging beneath its carrier aeroplane. It then detached, and fired its rocket motor. Within minutes, it had disintegrated and its pieces were scattered over an 8-kilometre-long swathe of the Mojave Desert.

Among other goals, the flight was meant to test a new type of rocket motor. Virgin Galactic decided in May to switch SpaceShipTwo's fuel from a rubber to a plastic base, in part to boost the spacecraft's final altitude. The fuel reacts with liquid nitrous oxide to propel the rocket. Hart said that the fuel and oxidizer tanks were found intact. In 2007, an explosion during a ground-based test with nitrous oxide killed three workers at Scaled Composites, the Mojave-based company that designed and built SpaceShipTwo.

SpaceShipTwo is a larger, eight-seat version of SpaceShipOne, the two-seater that won the US\$10-million Ansari X Prize in 2004 on becoming the first private vehicle to repeatedly reach an altitude of 100 kilometres.

Virgin Galactic had been selling seats on future flights, with up to 5 minutes of weightlessness, for $\$ 250,000$ each. Its customers include not only celebrities but also scientists who want to use it for microgravity studies. A second SpaceShipTwo is about $60 \%$ built. Meanwhile, a competing company, XCOR Aerospace of Mojave, is building a piloted space plane that would take tourists up one at a time.

The accident underscores the complexities of private spaceflight, where engineering systems are designed from scratch and tested in very public view. Many compare the endeavour to the early days of aviation, when aeroplane companies crashed time and again as they tried to commercialize air transportation. "To some degree, we are still in the infancy of spaceflight," says Scott Hubbard, director of Stanford University's centre of excellence for commercial space transportation in Palo Alto, California.

Commercial spaceflight will probably survive, analysts say, but only if the public is as willing to accept the risks as are aerospace experts. "I don't mind if it takes some time to develop," says Alan Stern, a planetary scientist at the Southwest Research Institute in Boulder, Colorado, who has signed up for a research seat on SpaceShipTwo. "I'm quite convinced that commercial suborbital flight will be safe." NASA is building a new launch system for astronauts, but it is space companies that are coming up with rockets and spacecraft designs.

As the space-tourism industry tries to assess its future, another area of commercial spaceflight is likely to keep forging ahead. Last week's failed Antares mission was part of a series of cargo flights to the International Space Station organized by Orbital Sciences of Dulles, Virginia, in partnership with NASA. An inquiry led by Orbital aims to find out why the rocket lifted briefly off its launch pad at Wallops Island, Virginia, before exploding and falling to the ground.

The next planned step for private companies will be flying US astronauts, as well as cargo, to the space station. In September, SpaceX of Hawthorne, California, and Boeing of Houston, Texas, won a contract to begin flying astronauts by 2017. Hubbard, who chairs a safety committee to review SpaceX's upcoming crewed flights, notes that Orbital is not in the running for those.

"Accidents with new technology are inevitable," says Johnson-Freese. "How they are handled is the true test of innovation and innovators." -

\title{
Future of Great Barrier Reef divides scientists
}

\section{Marine-park management comes under scrutiny as conservationists descend on Australia.}

\section{BY DANIEL CRESSEY}

\section{$\mathrm{T}$} he health of the world's most famous swathe of ocean real estate - the Great Barrier Reef Marine Park — will take centre stage next week as conservationists from around the world head to Sydney, Australia, for a once-in-a-decade meeting on ecosystem management. The park faces challenges, but scientists disagree over how endangered it is and how well it is being managed. Climate change further complicates the picture.

Every ten years, the International Union for Conservation of Nature hosts the World Parks Congress to decide how to use parks to promote conservation (see page 28). On 12-19 November, a particular focus will be how to enhance and expand marine parks (see 'Marine parks on trial'). Yet the Great Barrier Reef, which was once held up as a shining example of ecosystem management, has run into trouble.

Lying off the eastern coast of Australia, the park covers an area of ocean approximately the size of Germany, encompasses 3,000 coral-reef

systems and is the largest 'living structure' on Earth. It is managed by the Great Barrier Reef Marine Park Authority (GBRMPA), which has divided it into zones that impose different restrictions on activities, such as scuba diving or fishing.

This year, protests escalated over a proposed port expansion that would have dumped dredge material within the park boundaries. The plan was abandoned but the United Nations

\section{"The overall outlook for the Great Barrier Reef is poor and getting worse."}

Educational, Scientific \& Cultural Organization (UNESCO) will next year be deciding whether damage done to the park through degradation and development means that it should be included on the List of World Heritage in Danger. In August, the GBRMPA itself published a report warning that "the overall outlook for the Great Barrier Reef is poor and getting worse".

Among the evidence for problems is a muchcited 2012 study showing that coral cover had halved between 1985 and 2012 (G. De'ath et al. Proc. Natl Acad. Sci. USA 109, 17995-17999; 2012). The report placed much of the blame on cyclones and unusually large swarms of crownof-thorns starfish (Acanthaster planci), which eat reef-building corals.

Some believe that much of the damage is temporary. Aaron MacNeil, who is studing the Great Barrier Reef at the Australian Institute of Marine Science in Townsville, points out that two huge cyclones - Hamish in 2009 and Yasi in 2011 - hit the reef in a particular way, producing a combined battering expected just once every 600 years. "I think in general the Great Barrier Reef is in pretty good shape but it has had a rough few years of storm activity that have left coral cover unusually low," he says.

Others, however, say that things are worse than they seem. Marine palaeoecologist John Pandolfi at the University of Queensland in Brisbane has been using sediment cores and other methods to reconstruct the reef's history over the past 1,200 years. "I am afraid that if you compare the current state of the reef to the 


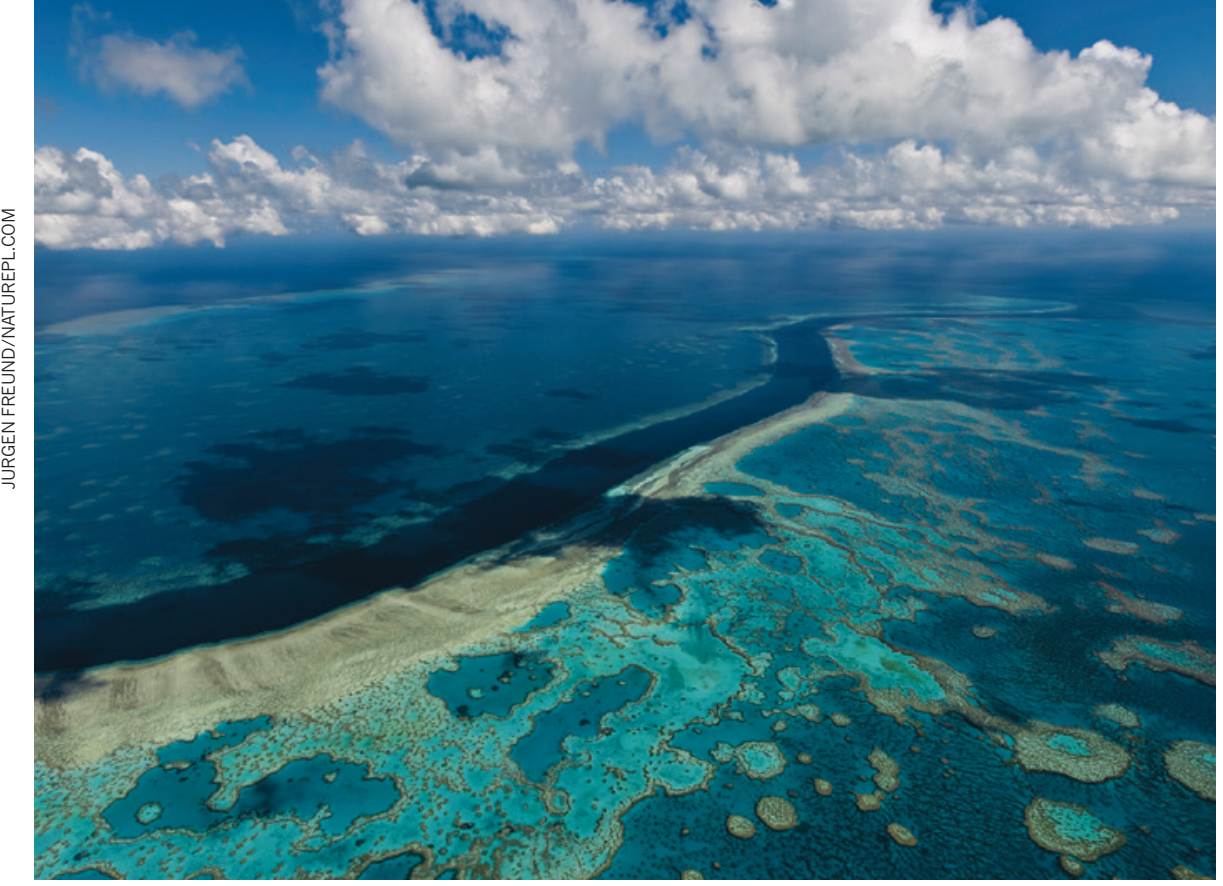

The Great Barrier Reef is struggling to cope with the impacts of climate change and development.

kinds of long timescales that my team looks at, then things are even worse than what you might have heard," he says.

Pandolfi's team has documented declines in Acropora corals, which are vital to the reef framework, that date back to the 1920s (G. Roff et al. Proc. R. Soc. B. 280, 20122100; 2013). The losses are probably linked to changes in agriculture that were brought in by European settlers and affected water quality and damaged the reefs. Current reports therefore may underestimate declines in reef quality because they are often based on comparisons to a degraded state of the reef, rather than its truly pristine state, an issue known as shifting baselines. The GBRMPA is using Pandolfi's work to try and address this problem.

Modern pressures include the effects of nearby land development, such as run-off fertilizer from farming. Russell Reichelt, the GBRMPA's chairman and chief executive, says that the threat from the proposed dredge dumping was overblown, but that the GBRMPA will encourage government and local businesses to adopt a policy whereby their activities have a positive net impact on the reef, not just a neutral one, as is the case now. It is also introducing targets for maintaining habitats and species as well as systems for assessing cumulative impacts.

Marine scientist Bob Kearney at the University of Canberra says that designating the reef as a marine park has fostered an "inappropriate" focus on fishing, given the bigger threat posed by climate change. The reef is highly sensitive to changing temperatures and ocean acidification, but global action is needed to tackle the carbon emissions that are the root cause of these issues. Similarly, last week, the Australian Academy of Science criticized a multimillion-dollar reef sustainability plan drawn up by the Australian and Queensland governments because it "fails to effectively address" any of the major pressures on the reef.

MacNeil is more optimistic, thanks to the current collaborative approach between the government, universities and the private sector to solving the reef's problems. "By working together I think we're in a better position to understand and address threats to the Great Barrier Reef than ever before," he says.

\section{MARINE PARKS ON TRIAL Indonesian corals in controlled test}

The effect of marine park areas (MPAs) parts of the ocean that are protected and managed for conservation - is difficult to tease out, not least because ocean ecosystems are affected by so many variables. Now, a study akin to a randomized controlled trial is aiming to do just that in the remote Bird's Head Seascape in Indonesia.

Sitting in the 'coral triangle' north of Australia, the seascape contains more than 2,000 islands, many of which have remained undeveloped. Gabby Ahmadia, a marine scientist at the conservation organization WWF, has been searching for areas that can be used as controls for seven newly created MPAs within the Bird's Head.

Distance from fishing markets and

exposure to waves, for example, must be matched between a park and its control. Ahmadia's team will then measure factors such as fish biomass to determine whether the park designation is making a difference. "We really need to get to the question of are these MPAs working, and, when they are working, why," she says. D.C.

\section{FUNDING}

\section{Basket of gifts for German science}

\author{
Despite looming recession, \\ research gets a windfall.
}

\section{BY QUIRIN SCHIERMEIER}


ermany's economy may be shaky, but its science is in rude health. On 30 October, ministers from the federal government and Germany's 16 states pledged $€ 25.3$ billion (US\$31.6 billion) over the next 6 years to support special programmes for research and higher education.

With a research-and-development expenditure of about $€ 100$ billion per year - some two-thirds of which is corporate money - Germany is the fourth-highest science spender worldwide, behind the United States, China and Japan. Public funding for special programmes remained strong even after the global financial crisis of 2008 . Now the windfall looks set to continue for the country's universities and large science organizations, despite drops in exports and industrial production that suggest that the economy could tip into recession.

The bulk of the money is for universities. Currently, some 2.6 million students are enrolled at Germany's roughly 300 universities - around 400,000 more than in 2005. First-year enrolment is projected to grow by 360,000 or so by 2020 . To cope, the federal government plans to continue a pact with the states, launched in 2007 , to jointly contribute nearly $€ 20$ billion by 2020 .

Ministers have also agreed to continue a deal that guarantees 4 non-university research organizations, including the Max Planck Society, annual budget increases of $3 \%$ until 2020. Since 2005, the combined budget of the four organizations, which run a total of 254 institutes and large research centres, has risen from $€ 5.2$ billion to $€ 7.9$ billion. The rises are not earmarked for particular fields, but national priorities include energy, specifically renewables, and health, owing to the ageing population.

The federal government also plans to boost the budget of its main grant-giving agency for university research by $5 \%$ next year to $€ 2.95$ billion, and by $3 \%$ annually from 2016 on. And ministers agreed in principle that the German Excellence Initiative, a $€ 4$.6-billion university competition for topup funds launched in 2006, may continue beyond its initial expiration year of 2017 . 